\title{
Towards an HPSG Analysis of Object Shift in Danish
}

\author{
Stefan Müller` and Bjarne Ørsnes \\ German Grammar, FU Berlin
}

\begin{abstract}
This paper develops an analysis of object shift in Danish. We suggest that object shift is best analyzed as an alternative mapping from the ARG-ST list to SPR and COMPS.
\end{abstract}

\section{Introduction}

Danish is an SVO language. This order is demonstrated by the following subordinated clause:

(1) at Jens har læst bogen that Jens has read book.DEF 'that Jens has read the book'

Apart from being an SVO language, Danish is a verb second (V2) language, that is, any constituent can appear in front of the position of the finite verb in declarative main clauses. (2) shows an example in which the object is fronted:

(2) Bogen har Jens læst. book.DEF has Jens read 'Jens has read the book.'

Adjuncts attach to the VP and are serialized either to the left or to the right. The negation obligatorily attaches to the left:

(3) at Jens ikke [vp læser bogen] that Jens not reads book.DEF 'that Jens does not read the book'

In V2 sentences the finite verb is inverted, that is, placed to the left of the subject. One common analysis in GB/Minimalism and HPSG is to assume that the inverted verb is related to a verb trace in the VP. (4) shows the structure:

\footnotetext{
* We want to thank the audiences of the Third International Workshop on Germanic Languages (With Special Focus on Scandinavian) that was held 2012 at the Freie Universität Berlin and the participants of the HPSG workshop in Frankfurt, 2012 for discussion. Special thanks go to Sten Vikner for intense discussion of object shift. This work was supported by the Deutsche Forschungsgemeinschaft (DFG MU $2822 / 2-1)$.
} 
(4) Jens læser ${ }_{i}$ ikke [vP $-i$ bogen]. Jens reads not book.DEF

The negation can then be used as an indicator that marks the left periphery of the VP even in sentences with an inverted verb.

This paper deals with a certain order that is required for personal, reflexive, or locative pronouns in a non-subject function. These pronouns do not occur in the canonical position inside the VP (to the right of sentential adjuncts), but rather outside the VP to the left of sentential adjuncts. The examples in (5) show that a full NP bogen ('the book') must occur inside the VP to the right of sentential negation. The examples in (6) show that the unstressed pronoun den ('it') occurs outside the VP linearly preceding the sentential adverb ikke ('not').

(5) a. Jens læser ikke bogen.

Jens reads not book.DEF

'Jens is not reading the book.'

b. * Jens læser bogen ikke.

Jens reads book.DEF not

(6) a. Jens læser den ikke.

Jens reads it not

'Jens is not reading it.'

b. * Jens læser ikke den.

Jens reads not it

The paper will be structured as follows: in the next section we discuss the shifting in double object constructions and interactions of verb inversion, verb fronting, and object shift (facts that are known under the term Holmberg's Generalization). We then briefly discuss alternative proposals in Section 3 and provide our analysis in Section 4. Section 5 draws some conclusions.

\section{The Phenomenon}

Object shift applies in verb initial (V1) or V2 clauses, but is not possible in embedded clauses without verb inversion: ${ }^{1}$

(7) a. at Jens ikke giver dem bogen

that Jens not gives them book.DEF

'that Jens did not give the book to them'

b. * at Jens dem ikke giver bogen

that Jens them not gives book.DEF

c. Jens giver $_{i} \operatorname{dem}_{j}$ ikke [ ${ }_{-i}-j$ bogen]

Jens gives them not book.DEF

\footnotetext{
${ }^{1}$ Note, that the traces are used to mark the positions that full objects would take. While we are using traces for verb movement in our analysis, we do not assume a movement-based approach of object shift.
} 
Object shift is strictly clause-bound (Vikner, 2006, p. 405). A pronoun can never shift into the matrix construction of an embedding verb. This situation would only obtain in a context with embedded V2, that is, when a verb selects a clause with verb fronting, since object shift is only observed in V1- and V2clauses. In clauses with embedded V2, a pronoun cannot shift across its selecting head into the matrix clause. In the examples in (8), the complement clause is V2 with the object forretten ('the starter') in position before the finite verb, the so-called the prefield. As (8b) shows the reflexive pronoun sig ('REFL') cannot occur in the matrix clause.

(8) a. Jeg ved at forretten brød han [sig] ikke om.

I know that starter.DEF cared he REFL not about

'I know that he didn't like the starter.'

b. * Jeg ved [sig] at forretten brød han ikke om.

I know REFL that starter.DEF cared he not about

While Icelandic allows full NPs to shift, shifting is limited to weak pronouns in Danish: As Mikkelsen (2011, p. 252) shows, shifted elements have to be unstressed and they may not be phrase structurally complex.

It is possible to shift both objects of a ditransitive verb (9a), but the relative order of the objects has to be preserved, that is, the indirect object precedes the direct object as in sentences with full objects (9c).

(9) a. Han giver ham det ikke.

he is.giving him it not

'He is not giving it to him.'

b. *Han giver det ham ikke.

he is.giving it him not

c. Han giver ikke manden bogen.

he is.giving not man.DEF book.DEF

'He is not giving the man the book.'

It is not possible to shift the DO over the IO, as the contrast in (10) shows:

(10) a. Han skænkede ikke biblioteket bogen.

he donated not library.DEF book.DEF

'He did not donate the book to the library

b. ?* Han skænkede ${ }_{j}$ den $_{k}$ ikke [ ${ }_{-j}$ biblioteket $\left.-k\right]$.

he donated it not library.DEF

'He didn't donate it to the library.'

Interestingly though, if the IO is extracted, the DO can be shifted:

(11) Biblioteket ${ }_{i}$ skænkede $_{j}$ han den $_{k}$ ikke $[-j-i-k]$.

library donated he it not

'He didn't donate it to the library.'

The only situation in which a DO can precede an IO is a configuration in which the DO is positioned to the left of the finite verb in the so-called prefield. (12) gives an example: 
(12) Bogen $_{k} \quad$ skænkede $_{j}$ han $\left[{ }_{-j}\right.$ biblioteket $\left.{ }_{-k}\right]$. book.DEF donated he library.DEF

Having discussed examples with transitive and ditransitive verbs we now turn to prepositional objects: Full PPs do not shift as (13) shows:

(13) a. Vi venter ikke på dig. we wait not for you 'We are not waiting for you.'

b. *Vi venter på dig ikke. we wait for you not

Shifting of a pronoun out of a $\mathrm{PP}$ is also impossible despite the general possibility of $\mathrm{P}$ stranding:

a. * Vi venter dig ikke på. we wait you not for Intended: 'We are not waiting for you.'

b. Dig venter vi ikke på. you wait we not for 'We are not waiting for you.'

The generalization about the data is that shifted elements have to be arguments of a verb. This generalization also captures valence-bound locatives.

V2 clauses (for instance, (2) and (14b)) are analyzed as nonlocal dependencies (that is, movement in GB/Minimalism and SLASHed categories in GPSG/HPSG), since the element before the finite verb may be a dependent of a deeply embedded head. The question now is whether reorderings of pronouns should be treated with the same mechanisms. There is evidence against analyses that treat shifting parallel to extractions of the prefield filling kind: For instance, Holmberg (1999, p. 18) and Vikner (2006) discussed shifted pronouns and argued that they do not license parasitic gaps. Extracted elements like hvad for en bog ('which book') in (15a) licence a second gap in an adjunct as for instance the phrase uden at lese først ('without reading first') (see Vikner 2006, p. 11 for a discussion of the examples in (15)). In example (15a) the fronted wh-constituent hvad for en bog ('which book') is co-indexed with a gap in the object position of the verb stille ('to put'). This gap, in turn, licenses the second gap (the object of lese ('to read')). If shifted pronouns would leave a trace inside the VP, we should expect them to be able to license parasitic gaps. However, in example (15b) the shifted object den ('it') is co-indexed with the first gap, and here the second gap (the object of lase ('to read')) is not licensed.

(15) a. [Hvad for en bog $]_{i}$ stillede alle $-i$ hen på reolen uden at which book put all onto bookcase.DEF without to læse $-i$ først?

read first

'Which book did everyone put on the shelf without reading first?' 
b. * Alle stillede den $\operatorname{den}_{i}$ straks uden at all put it immediately onto bookcase.DEF without to læse $-i$ først. read first

'Everyone put it on the shelf without reading it first.'

This suggests that there is a fundamental difference between object shift and extraction to the prefield.

The examples in (7) showed that object shift does not occur in embedded clauses, that is, pronouns do not shift over finite verbs. The same observation can be made with regard to non-finite verbs:
a. Jeg har ikke kysset hende.
I have not kissed her
'I hav not kissed her.'
b. * Jeg har hende ikke kysset.
I have her not kissed

But the shifting of pronouns becomes possible if the non-finite verb is extracted (Vikner, 2006, p. 407):

a. Kysset ${ }_{i}$ har $_{j}$ jeg hende $k$ ikke $[-j-i-k]$, bare holdt hendes hånd. kissed have I her not only held her hand 'I have not kissed her. I only held her hand.'

b. men helt [udelukke] kan man [det] da ikke eller hvad ${ }^{2}$ but wholly exclude can you it then not or what 'but you cannot wholly exclude it, can you?'

The facts about the necessity to invert the verb to V1/V2 order, to extract the non-finite verb, and to extract the IO if the DO is shifted have subsumed under Holmberg's Generalization (1999) in Transformational Grammar: Pronouns can shift only if they are the left-most overt element in the VP. This explains, why the finite and the non-finite verb has to be out of the way and why the DO cannot shift unless the IO is extracted. However, as will be shown in Section 3 a purely movement-based proposal runs into problems. A different way to describe the situation is to say that the verbs have to precede their arguments independent of shifting and that the IO has to precede the weak pronominal DO independent of extraction and shifting. (Note that weak pronouns cannot occupy the prefield, so the statement just made cannot be falsified by DO extractions to the prefield.)

\section{Previous Analyses}

\subsection{Cliticisation}

Erteschik-Shir (2005) suggested a cliticization approach to object shift. She assumes that weak pronouns cannot be pronounced on their own and hence must

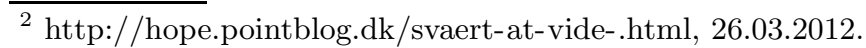


incorporate into a host. In her approach adverbials (by stipulation) cannot serve as hosts for prosodic incorporation and hence the pronoun must shift over adverbials. In an example like (18) the pronoun attaches to the subject and subject, pronoun, and negation form a prosodic unit.

(18) Læser Peter+den+ikke?

reads Peter+it+not

'Dosn't Peter read it?'

As Holmberg (1999, p. 28, Footnote 26) pointed out while discussing Hellan's analysis of object shift in Norwegian (1994), the analysis in Erteschik-Shir (2005) fails to explain why a weak pronoun also has to shift in the presence of a PPadjunct. In the examples in (19) the sentential adjunct is syntactically a PP with a preposition and a DP object. Therefore, we should expect the pronoun to be able to incorporate into the DP stor sandsynlighed ('great probability'), given that DPs are possible hosts for phonological incorporation. But the pronoun does not incorporate into these constituents, instead it shifts.

a. *Hun kender med stor sandsynlighed ham ikke. she knows with big probability him not Intended: 'It is most likely that she doesn't know him.'

b. Hun kender ham med stor sandsynlighed ikke. she knows him with big probability not

Finally, Holmberg (1999, p. 27) pointed out another problem for the clitic analysis: it does not extend to object shift in Icelandic and Faroese that allow for complete NPs to undergo object shift.

\subsection{Movement}

As was shown in Section 2 the parasitic gap data is evidence against movementbased approaches. Furthermore there are problems, if one wants to capture Holmberg's generalization in a movement approach. To see this consider the analysis in Figure 1 on the facing page. If the DO can move only when the IO has moved already, the IO would have to move and to attach to the VP (or IP). The DO would be the next thing to move. However, the resulting order is ungrammatical and there is no way to get the correct order, if Holmberg's view has to play a role in the analysis.

\subsection{Linearization-Based Analyses}

Bjerre (2006) suggested a linearization-based approach in the framework of HPSG. In such approaches the dependents of a head are inserted into one flat list and linearization rules (LP rules) restrict the possible linearizations of elements in this list (Reape, 1994). Bjerre assumes traditional topological fields and sets up the LP statements accordingly.

Consider the analysis for the sentence in (20) which is given in Figure 2 on the next page: 


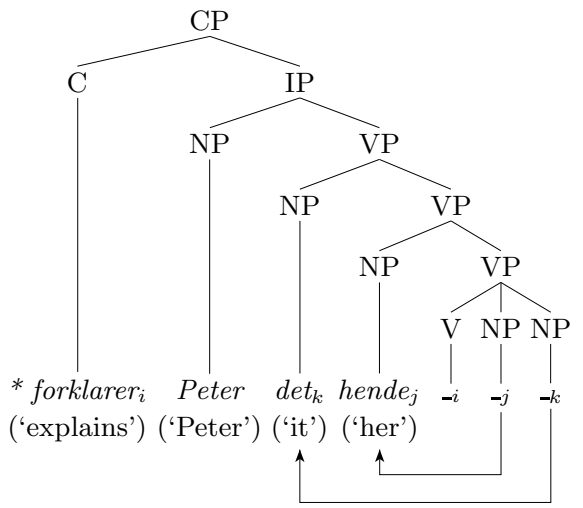

Figure 1. Problems for movement-based approaches

(20) at Jens læser bogen

that Jens reads book.DEF

'that Peter reads the book'

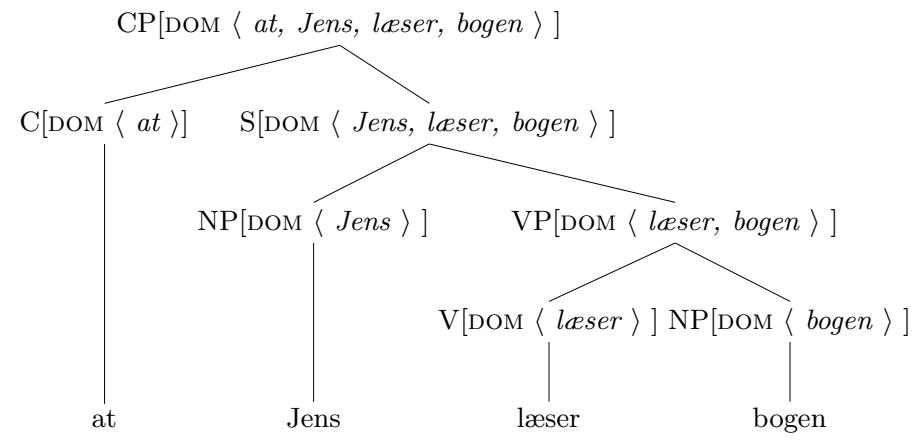

Figure 2. Linearization-based analysis of Danish clauses

The domain objects are complex linguistic objects that are similar to the ones that we are using here. In the figure only the PHON values are given. Every lexical item comes with a domain object that represents its phonological, syntactic, and semantic properties. When a complex object is build, the domain objects of the daughters are inserted into the domain of the mother node. As Figure 2 shows, we end up with a flat representation of all constituents at the top-most node in the tree.

Bjerre (2006) suggests that syntactic functions are assigned to syntactic positions (by means of an appropriate type hierarchy) and that linear precedence is stated in terms of these syntactic positions. The type verbal is assigned to the position $m$ (corresponding to the fronted position) and the position $V$ (the base position within the $\mathrm{VP}$ ). The syntactic function object is assigned to the 
positions I and N, saying that an object can occur in position I (the position for shifted objects) or in the position N (the position of full NP objects within the VP). $n$ is the field for the subject and $a 1$ the field for VP adjuncts. $F$ is the field the corresponds to the prefield. The order of elements on the DOM list is constrained by precedence rules of the following (simplified) kind.

$$
F<m<n<I<a 1<V<N
$$

Figure 3 shows our example augmented with the negation ikke and with the topological field assignment. The interesting case is now the analysis of object

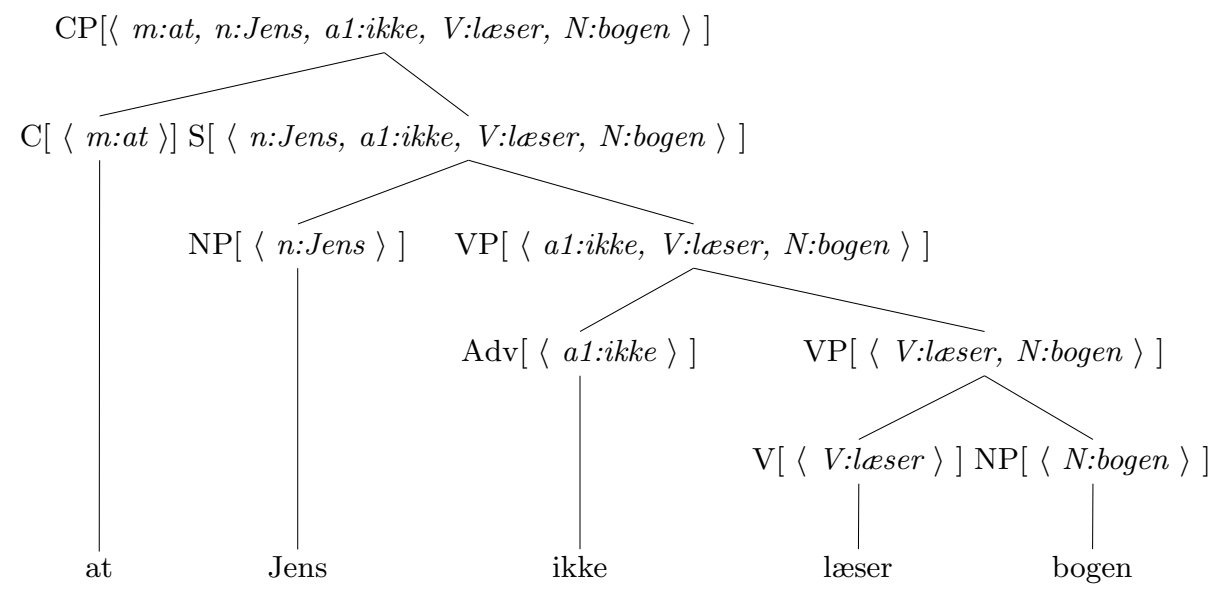

Figure 3. Linearization-based analysis of Danish clauses with topological labels

shift, which has the same structure as the non-shifted example but a different linearization. The analysis is given in Figure 4 on the next page. ${ }^{3}$ The object pronoun is assigned to the field $I$ rather than $N$ and hence is linearized to the left of the adverb. Since the verb is assigned to the field $m$ it precedes both the shifted pronoun and the adverb. It should be clear from the pictures that in linearization-based analyses the dominance structure is independent of the actual serialization of components. In particular discontinuous constituents are allowed in such models.

According to Bjerre the elements that are inserted into the prefield are inserted as a single domain object. With these basic assumptions it is unclear how the following example can be captured:

\footnotetext{
${ }^{3}$ Bjerre assumes that objects that are positioned in the prefield are licenced there in head-filler structures. Probably he would apply this to subjects as well. Figure 4 would have to be augmented with a trace in the subject position and a Head-Filler combination at the top of the structure. However, this would not change the DOM values and assignment of topological fields, since traces are assumed to not contribute any domain objects.
} 


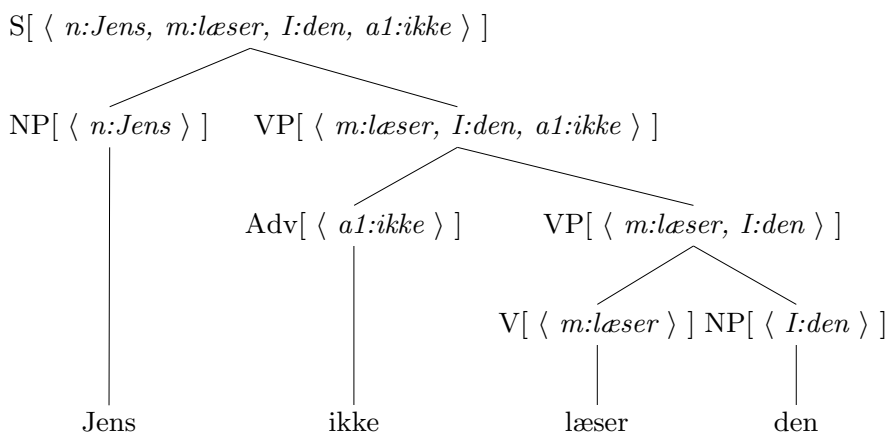

Figure 4. Linearization-based analysis of object shift

(22) Læst har Jens den ikke.

read has Jens it not

'Jens did not read it.'

The problem is that the argument of the auxiliary verb har ('has') is a VP, but the VP is discontinuous in (22) since the object den ('it') appears in shifted position to the left of the negation. One could claim that auxiliaries form a single linearization domain with the verb that they embed and with the arguments of the embedded verb. This would be the clause union analysis that Reape suggested for the treatment of so-called coherent constructions in German, that is, for verbal complex formation. However, this would overgenerate, since this would allow sentences like (23):

(23) * Læst har Bjarne ikke bogen read has Bjarne not book.DEF 'Bjarne did not read the book.'

The problem with (23) is that the object of laest ('read') is a full noun. It is not possible to front bare verbs in Danish, if the object is a full NP. If the object is a full NP it has to be fronted together with the verb as in (24):

(24) Læst bogen har Bjarne ikke read book.DEF has Bjarne not 'Bjarne did not read the book.'

This is explained in approaches that assume that the argument of the auxiliary verb is a VP, that is, a verbal projection that includes all complements. Note that (23) cannot be ruled out by linearization constraints that refer to traditional topological fields since all constituents are in fields in which they can be linearized: The full NP is to the right of the negation as in (5a), the finite verb is in second position and the non-finite verb is in the prefield as in (22).

The problem could be solved by assuming partial compaction of domain objects à la Kathol and Pollard 1995. In such an approach one domain object would be inserted into the prefield if the object is a full NP and two objects 
would be inserted into the matrix domain if the object in the extracted VP is a pronoun. Such an approach seems to be stipulative since it would have to formulate a complicated mechanism that applies only to the domain insertion of extracted VPs.

\section{The Analysis}

This section will provide an analysis in the framework of HPSG (Pollard and Sag, 1994). We will give the background assumtions in Section 4.1, develop the core of the analysis in Section 4.2. Section 4.3 deals with prepositional arguments and Section 4.4 describes the analysis of partial fronting and Section 4.5 explains how Holmberg's Generalization is captured in the analysis.

\subsection{Background}

Following Pollard and Sag (1994, Chapter 9) we assume that arguments of a head are represented in a list that is ordered according to the obliqueness hierarchy, that is, in the order Subj < IO < DO < Obliques (Pollard and Sag, 1992, p. 266, 280). In recent publications this list is called the argument structure list (ARG$\mathrm{ST}$ ). The elements from the ARG-ST list are mapped to the valence features SPR and COMPS. SPR stands for specifier and COMPS for complements. The SPR list may contain the determiner of an NP or the subject of a verb. (25) shows an example of a lexical item of a ditransitive verb with the arguments in the ARGST list linked to the semantic contribution of the verb and with the respective mapping to SPR and COMPS:

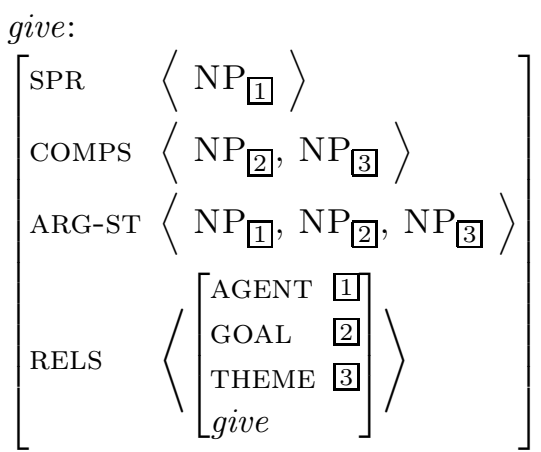

We follow Müller (To appear) in assuming binary branching structures and hence assume binary branching schemata for specifier head and head complement combinations. The analysis of an embedded clause is shown in Figure 5 on the facing page. The verb is combined with the IO first and the resulting object is combined with the DO and the result of this combination is a complete VP (the abbreviation VP stands for a linguistic object with the head category verb and an empty COMPs list). The VP is combined with the specifier to the left 


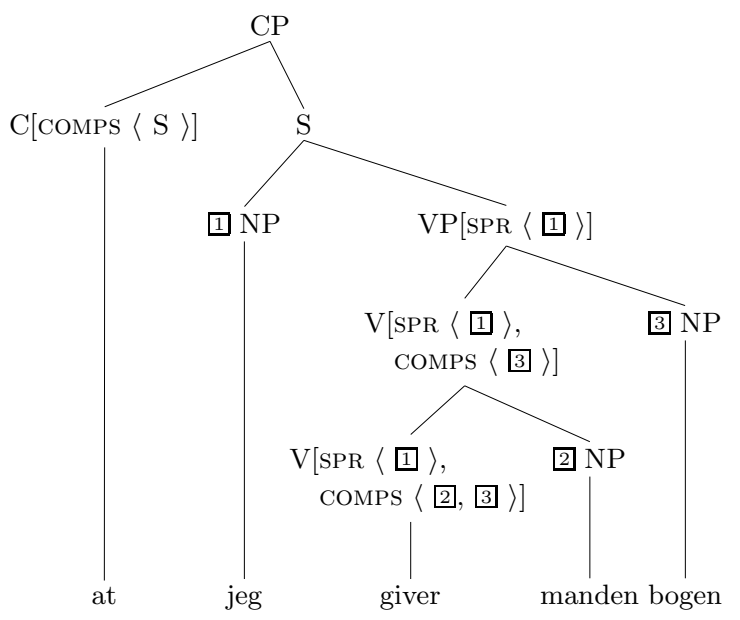

Figure 5. Analysis of at jeg giver manden bogen ('that I give man.DEF book.DEF')

resulting in a complete clause (abbreviated as $\mathrm{S}$ ). The complementizer selects for an $\mathrm{S}$ and the result of the combination of complementizer and $\mathrm{S}$ is a $\mathrm{CP}$.

For the analysis of V1 and V2 sentences we follow proposals by Borsley (1989b) for English and Kiss and Wesche (1991); Kiss (1995); Meurers (2000); Müller (2007b) for German and assume a head movement analysis. The head movement analysis has the advantage that a uniform treatment of VP adjuncts is possible: the adjuncts attach to the left or to the right of VP and there is no difference between main and embedded clauses in this respect. The Danish verb inversion is similar to auxiliary inversion in English except that it applies to all finite verbs. While analyses involving empty elements should be avoided if possible it has been shown that so-called multiple frontings in German are best analyzed as combinations of the fronted elements with an empty verbal head. This empty verbal head is availible in verb movement analyses and the verb movement analysis blends nicely with the analysis of multiple frontings (Müller, 2005). So, we assume that it is justified to treat these closely related Germanic languages in a parallel way and hence assume a verb movement analysis for Danish as well.

The analysis is sketched in Figure 6 on the next page. The verb laser is mapped into a verb that selects for a saturated verbal projection (an S) that contains a verbal trace (represented as '//V'). The DSL feature that is used to represent information about the missing verb is a head feature and hence the information is percolated through the tree to the verb trace. In the verb trace the DSL value is shared with the LOCAL value of the trace and hence the verb trace has the same LOCAL value as the verb in initial position. In the case of our example this means that the verb trace selects for an NP via COMPS and for another one via SPR. The verb trace forms a VP with its complement. This VP is modified by ikke ('not') and afterwards combined with its subject in a head- 


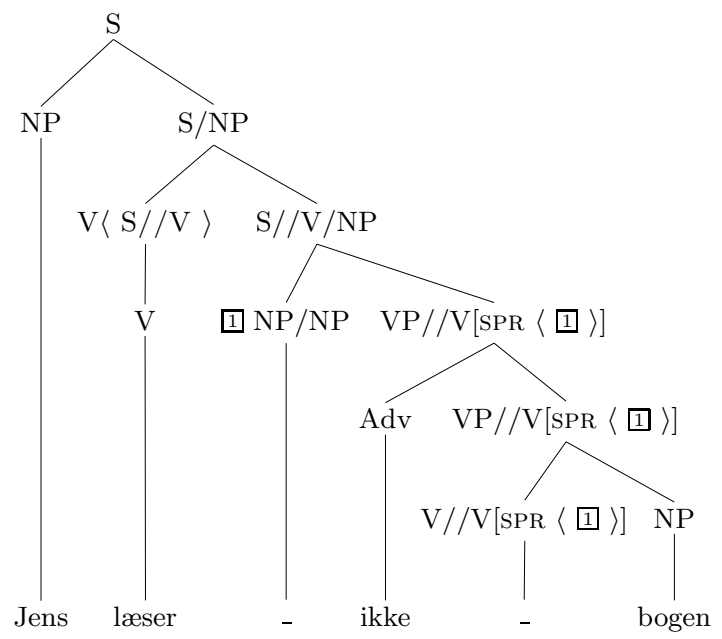

Figure 6. Analysis of the V2 sentence Jens laeser ikke bogen. ('Jens reads not book.DEF

specifier-phrase. The subject is a trace and the information about the missing constituent is percolated up to the mother nodes until it is finally bound off by the element in the prefield.

Danish is a language with rather fixed constituent order. The correct order of the objects in sentences with ditransitive verbs is guaranteed by combining the verb with its argument in order of their obliqueness, that is, the verb is combined with the IO first and the result of this combination is combined with the DO. However, there are languages with much freer constituent order. For instance, languages like German basically allow the arguments to be combined in any order with the verb. The Head Complement Schema of German will not be sensitive to the ordering of the complements on the COMPS list but allows the combination of a verb or verbal projection with any of the elements on its COMPs list that has not been saturated yet. While it is easy to enforce the relative order of a head with respect to its arguments and adjuncts in a system with binary branching structures, it is not obvious how LP constraints that order the complements relative to each other can be enforced. For instance there is a tendency for short elements (for instance pronouns) to precede heavy constituents. Of course one way of enforcing the order among coarguments is to licence all possible orderings in the lexicon (Uszkoreit, 1986) but this would result in a combinatorical explosion in the lexicon and spurious ambiguities that have to be excluded by ad hoc stipulations (Müller, 2004, p. 217-218). The alternative is to have a representation that corresponds to the linearization domain that one would have if one assumed flat structures. Therefore we assume a list in which all dependents of a head are inserted (the DOMAIN list of Reape (1994)). However, our approach is more restrictive than Reape's proposal in not allowing discontinuous constituents. 


\subsection{Object Shift as Alternative Mapping to Valence Features}

The key feature of our analysis of object shift is an alternative mapping to the valence features. We assume that weak pronouns may be mapped to the SPR list rather than to the COMPs list, which would be their usual place. The following lexical item shows the CAT value for the verb laeser ('to read'):

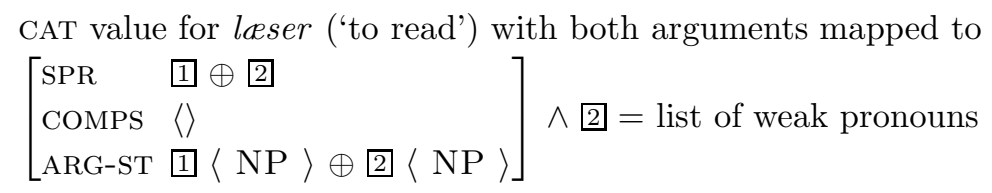

Rather than just mapping the first element of the ARG-ST list onto the SPR list, both arguments are mapped to the SPR list. Note that we do not claim that both arguments are subjects. Any properties that are specific to subjects and do not hold of all members of the SPR list have to be stated as constraints on the first element of the ARG-ST list in our approach. Note also that there are earlier proposals in the HPSG framework that suggested listing the subject in certain languages on the COMPS list (Borsley, 1989a for Welsh; Pollard, 1996 and following Pollard almost all researchers working on German) and similarly there are other analysis that map more than one argument to the valence list that usually contains a single subject (see Grover 1995 for an analysis of missing object constructions in English and Hahn 2012 for an analysis of so-called broad subjects in Arabic. We are also aware of the fact that predicative NPs require a determiner and a subject which they predicate over. The determiner and the subject are usually selected via different valence features. For predicative constructions, we follow Pollard (1996) and Kiss (1992) and assume a head feature SUBJ. While elements in SPR can be combined with their head in principle, this is never possible for elements in the SUBJ list, since there is no schema that refers to this head feature. See Müller 2009 for details on Predication.

The analysis of the example with a shifted pronoun is parallel to what we saw in Figure 6. The only difference is that the object is not realized as a complement but as a specifier. The respective analysis is shown in Figure 7 on the following page. The fact that laeser starts out as a VP may seem strange, but VP is just a shorthand for a verbal object with an empty COMPs list. As was shown in (26), laeser has both arguments in the SPR list. The V1 rule licences a verbal item that selects for a fully saturated clausal projection with a verbal trace that has the properties of laser, that is, a verbal trace with two elements in the SPR list and an empty COMPS list. Since the information about the missing verb (the DSL value) is a head feature it is present at the verbal trace as well and since the DSL value of the verbal trace is identified with the LOCAL value of the trace, it is ensured that the verbal trace has the right properties. The adverb ikke selects for a VP and the combination of adverb and verbal trace can be combined with the two specifiers. The first specifier is the shifted object and the second specifier is a trace of the subject, which is bound off later in a head-filler structure.

It remains to be explained why the adverb cannot combine with a projection that consists of the VP and one specifier as in Figure 8 on the next page. This 


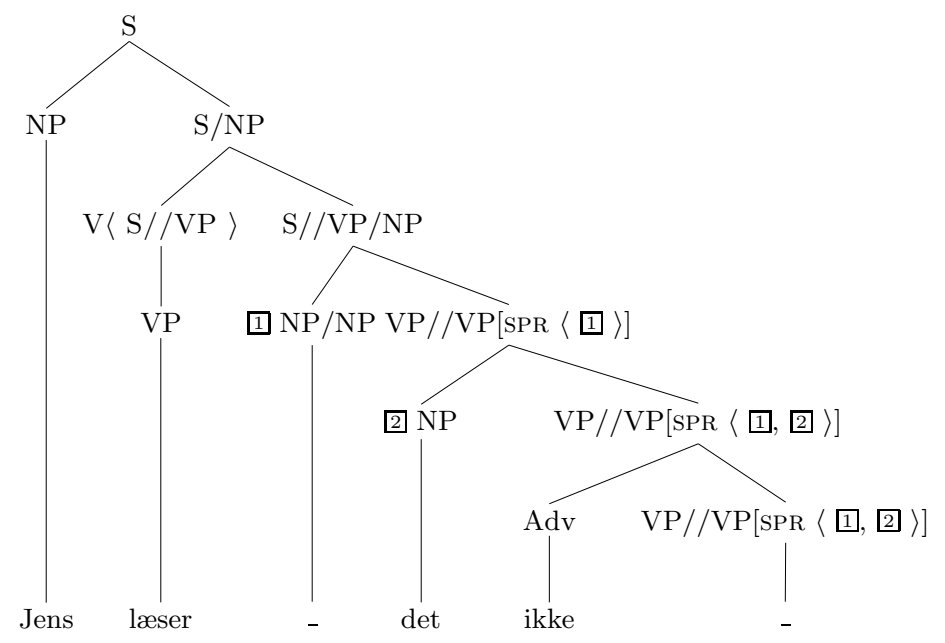

Figure 7. Analysis of the sentence Jens laser det ikke. with object shift with a transitive verb

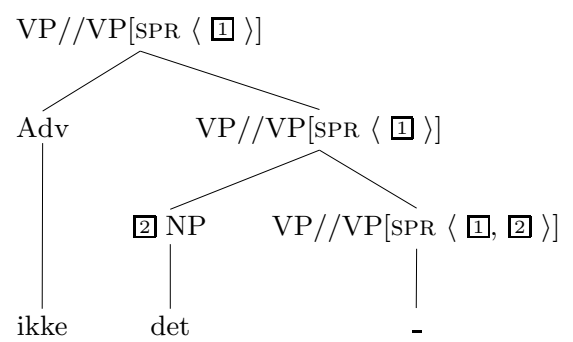

Figure 8. A structure that is ruled out by a linearization constraint requiring the weak pronoun to precede the adverb

structure is ruled out by a linearization constraint that requires shifted pronouns to precede adverbials. As was explained in Section 4.1, we assume that every head has a linearization domain into which the non-head sisters are inserted. Therefore the weak pronoun det ('it') and the adverbial ikke ('not') are in the same linearization domain and their relative order can be enforced by an LP constraint. Hence, the whole structure in Figure 8 is ruled out, while the one in Figure 7 does not violate the linearization constraint.

An alternative way of ruling out the structure in Figure 8 would be to require that the VP that the adverb combines with does not have any specifiers realized yet. This can be done easily in versions of HPSG that keep saturated arguments on the valence lists (Meurers, 1998; Przepiórkowski, 1999; Müller, 2008; Bender, 2008). Due to space limitations we did not introduce this concept here. 


\subsection{Shifting and Prepositional Objects}

As was shown in Section 2, prepositional objects do not shift and neither do NPs inside of prepositional objects. This is explained by our analysis, since appart from the subject only light pronominals can be mapped to the SPR list. ${ }^{4}$ So for the verb arbejder ('to work') there is only one mapping possible:

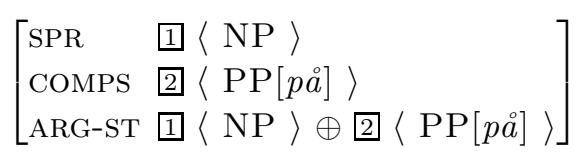

Since complements licensed by the Head Complement Schema have to be realized to the right of the verb (or verb trace), it is clear that full PPs cannot precede the verb or the negation. This explains the ungrammaticality of (14a). For the same reasons sentences like (14b), repeated here as (28), are ruled out: There is no way for the NP object of the preposition to get into the SPR list of the verb and hence it cannot be realized to the left of the negation. The NP argument of the preposition can be extracted but then it has to be realized in a Head-Filler configuration in the prefield.

(28) *Vi venter [dig] ikke [på]. we wait you not for

Intended: 'We are not waiting for you.'

\subsection{Partial Fronting}

We assume passive and perfect auxiliaries to be raising verbs that just take over the SPR list of the verb that they embed. Auxiliaries are assigned the following argument structure:

(29) argument structure of the passive and perfect auxiliaries:

$$
[\text { ARG-ST } 1 \oplus\langle\operatorname{VP}[\operatorname{SPR}[]\rangle]
$$

This argument structure is mapped to SPR and COMPS in the following way:

(30) argument structure and valence of the passive and perfect auxiliaries:

$$
\left[\begin{array}{ll}
\operatorname{SPR} & \square \\
\operatorname{COMPS} & \langle\mathrm{VP}[\mathrm{SPR} \square]\rangle \\
\mathrm{ARG}-\mathrm{ST} & \square \oplus\langle\mathrm{VP}[\mathrm{SPR} \square]\rangle
\end{array}\right]
$$

\footnotetext{
${ }^{4}$ It remains an open question why PPs cannot shift in Icelandic. Icelandic does allow shifting of full NPs and therefore a constraint on weakness could not be assumed to rule out the shifting of PPs (Engels and Vikner, 2012, p. 19). Engels and Vikner (2012, p. 76) suggest an OT constraint STAYBRANCHNoCASE that says that branching constituents that do not get case must not be moved. This is basically a stipulation of the observable facts and of course we can stipulate an analogous constraint.
} 
The example in (17), which is repeated as (31) for convenience, can then be analyzed as shown in Figure 9 on the facing page.

(31) Kysset har jeg hende ikke.

kissed have I her not

'I have not kissed her.'

In (31) the object of kysset ('kissed') is shifted. This means that the analysis of (31) involves a lexical item for the participle that has an empty comps list and two elements on the SPR list. As far as the valence features are concerned, this is parallel to the lexical item for leeser with a shifted object that was given in (26) on page 81. The difference between laser and kysset ist that the former is a finite verb and hence has the VFORM value finite, while the latter is a past participle and therefore has the VFORM value perf. The respective specification of kysset is provided in (32):

(32) CAT value for past participle kysset ('kissed') with both arguments mapped $\left[\begin{array}{ll}\text { to SPR: } & {\left[\begin{array}{ll}\text { VFORM } & \text { perf } \\ \text { verb }\end{array}\right]} \\ \text { SPR } & 1 \oplus \square \\ \text { COMPS } & \langle\rangle \\ \text { ARG-ST } & \square\langle\mathrm{NP}\rangle \oplus \square\langle\mathrm{NP}\rangle\end{array}\right] \wedge \square=$ list of weak pronouns

The perfect auxiliary have ('to have') selects for a VP with the VFORM value perf.

Since the lexical item for kysset has an empty COMPs list, it can function as the VP complement of the auxiliary. In the analysis of (31) the VP argument of the auxiliary is realized in the prefield. The VP in the prefield is connected to an extraction trace that functions as the complement of the verb trace. The verb trace has the same syntactic properties as the auxiliary in initial position, that is, it selects for a VP and attracts the SPR list from this VP in the way that was depicted in (30). The result of combining the verb trace and the VP trace is a VP that has two elements in its SPR list. This VP is combined with the negation and after this the two specifiers are realized.

There is a language particular fact about Danish that has not been mentioned so far. Partial fronting is possible with single verbs only. So either a full VP is fronted as in (33a) or a lexical verb as in (33b). In the latter case all objects of the verb have to be shifted.
a. Foræret
Anne bogen har Peter ikke. given.as.a.present Anne book.DEF has Peter not 'Peter has not given Anne the book as a present.'
b. Foræret har Peter hende den ikke. given.as.a.present has Peter her it not 'Peter has not given it as a present to her.'

Fronting verbs with some of their arguments in the fronted VP is ungrammatical: 


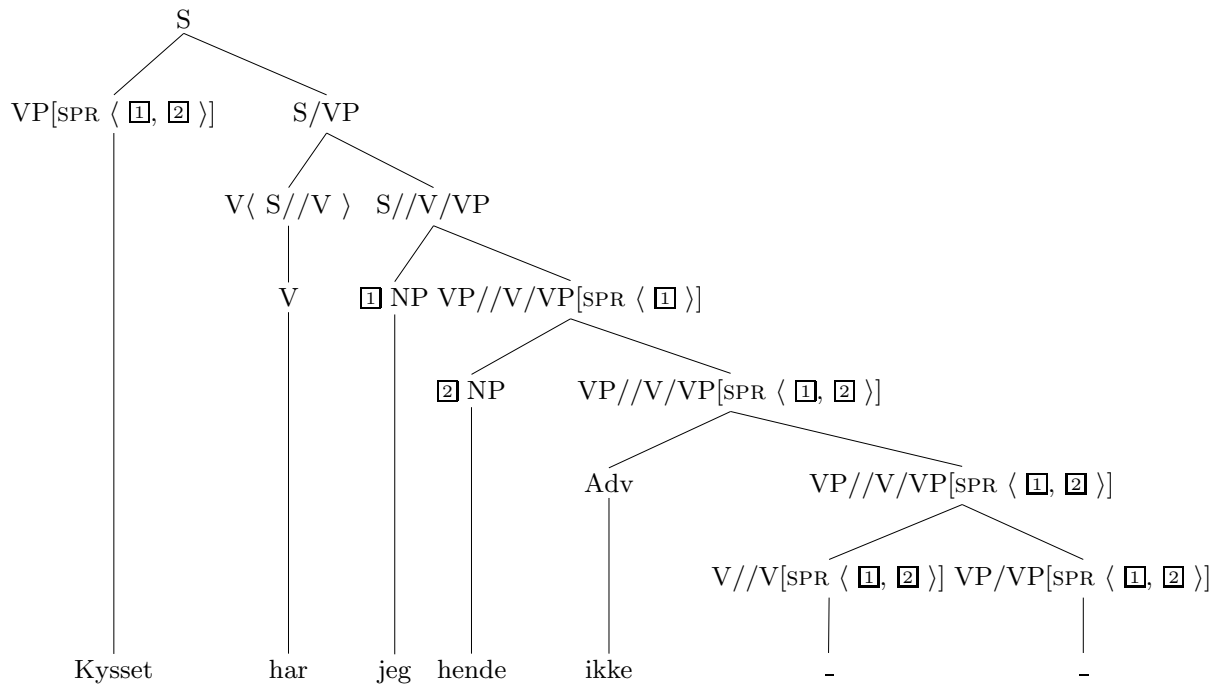

Figure 9. Object shift with perfect tense and partial VP fronting

$(34)$
* Foræret
bogen har Peter hende ikke.

given.as.a.present book.DEF has Peter her not

Intended: 'Peter has not given her the book as a present.'

This can be captured by the following constraint on head filler phrases: ${ }^{5}$

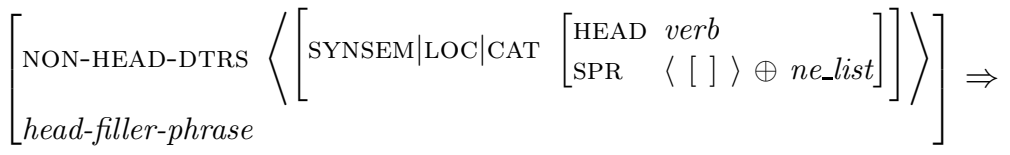

$$
[\text { NON-HEAD-DTRS }\langle[\text { SYNSEM } \mid \text { LEX }+]\rangle]
$$

This constraint says: If the filler daughter has more than one element in the SPR list (that is, we have a case of object shift and hence a partial VP), the filler daughter has to be LEX+, that is, a lexical verb. We assume that the HeadArgument Schema specifys the LEX value of the mother node to be '-' and hence combinations of verbs with one ore more of their dependents would be ruled out by $(35)$.

The constraint does not affect frontings of complete VPs, which are possible in Danish. A full VP has exactly one element in the SPR list and hence does not match the antecedent of the implication in (35).

\footnotetext{
${ }^{5}$ Engels and Vikner (2012, p. 109) discuss Danish data similar to Swedish data from Fox and Pesetzky 2005, which is discussed below in (37). These examples contain ditransitive verbs with one argument fronted and one left behind. We do not find the Danish examples acceptable. Speakers who admit such examples do not have the constraint in (35) in their grammars.
} 


\subsection{Holmberg's Generalization}

The fact that object shift is only possible if the left-most element is shifted can be captured by two LP constraints, which may be surprising at first glance. ${ }^{6}$ The constraints are given in (36):

$$
\begin{aligned}
& \text { a. } \mathrm{V}<\operatorname{Pron}[\neg \text { nom, weak }+] \\
& \text { b. } \mathrm{IO}<\mathrm{DO}
\end{aligned}
$$

(36a) ensures that the pronoun may not be shifted over a verb and hence for shifting to be possible, the finite verbs have to be inverted and non-finite verbs have to be extracted. In a first attempt to capture the data, we formulated a constraint that required that heads with multiple specifiers that enter a headspecifier structure are required to be phonologically empty. While this is sufficient to rule out sentence like (7b), it does not capture that the fronting of non-finite verbs is required as well. In order to explain the ungrammaticality of sentences like (16b) we had to state a separate constraint to the effect that heads that select for more than one specifier and a VP require their VP argument to be extracted. That is, the fact that weak pronouns cannot be reordered across verbs was stated as a conjunction of two rather specific constraints that affected two different types of 'movement': head movement and non-head movement. Instead of the two complex constraints that we proposed earlier, we now use the linearization rule in (36a), which captures the phenomenon rather directly.

In addition to the LP statement in (36a), we assume the constraint in (36b), which requires the IO to shift or to extract for DO shift to be possible. In an earlier version of our analysis we assumed that a prefix of the ARG-ST list has to be mapped to SPR. If extracted elements are not mapped to the valence features, it follows that the DO cannot be mapped to the SPR list unless the IO is either mapped to SPR or extracted. While this is a rather nice approach for Danish, it does not extend to Swedish. As the following examples by Fox and Pesetzky (2005, p. 25) show, Swedish is more liberal than Danish in allowing partial frontings like (37):

$$
\begin{aligned}
& \text { a. ? Get henne har jag den inte. } \\
& \text { given her have I it not } \\
& \text { b. * Get den har jag henne inte. } \\
& \text { given it have I her not }
\end{aligned}
$$

The point about these examples is that an account that relies on mapping prefixes of ARG-ST onto SPR would predict the oposit judgement, that is, (37a) should be impossible and (37b) marked but possible. What is needed to account for $(37 \mathrm{a})$ is the possibility to map the DO to SPR and realize the IO in the fronted VP. So, the mapping from ARG-ST to SPR has to allow more than just prefixes

\footnotetext{
${ }^{6}$ See also Engdahl, Andréasson and Börjars 2004 for an analysis in Optimality Theory that relies on linearization constraints. While it is possible to introduce into HPSG ranked linearization constraints in the spirit of Uszkoreit 1987, Section 3.1, we do not assume factorial typology.
} 
of ARG-ST to appear in the SPR list. For (37b) one would assume, as we do for Danish, that it is ruled out since the DO is serialized before the IO and hence violates the linearization rule in $(36 \mathrm{~b})$.

Note, that the DO is part of the VP get den. In order for the linearization rule in (36b) to apply to IO and DO in (37b), the IO and DO have to be members of the same linearization domain. We assume that VP complements are domain unioned into the domain of the auxiliary (Reape, 1994). For (37b) this results in a linearization domain that contains the linguistic objects that correspond to the words of this sentence. In this respect our approach is rather similar to the one suggested by Bjarre, but it differs in not allowing for discontinuous constituents. Therefore the VP get den is always realized continuously and problems like those that were discussed above are avoided.

It is also important to note here that traces do not contribute anything to the linearization domains. If they would, sentences like (11) were ruled out since the DO den preceedes the trace of the $\mathrm{IO}_{-i}$.

\section{Conclusion}

In this chapter we have presented an analysis of object shift in Danish without assuming any kind of movement or dislocation and without reducing object shift to a mere linearization phenomenon. We have suggested that lexical pronouns are members of the SPR list of their verbs. The analysis of auxiliaries and partial fronting involves argument attraction as in analyses of German partial verb phrase fronting (Müller, 1996, 1999, 2002; Meurers, 2000), but the arguments are attracted from the SPR list rather than from the COMPS list.

Linearization constraints account for the observations that have been summarized as Holmberg's Generalization.

The analysis has been partly implemented in the TRALE system (Meurers, Penn and Richter, 2002; Penn, 2004; Müller, 2007a) as part of a grammar fragment of Danish which uses a core grammar for German, Mandarin Chinese, Persian, Maltese, and Yiddish. See Müller 2013 on the CoreGram project. The respective grammars can be downloaded at http://hpsg.fu-berlin.de/Projects/ CoreGram.html. The Danish grammar is described in Müller and Ørsnes In Preparation.

\section{Bibliography}

Bender, E. M. 2008. Radical Non-Configurationality without Shuffle Operators: An Analysis of Wambaya. In S. Müller (ed.), Proc. Int. Conf. Head-Driven Phrase Struct. Grammar, pp 6-24, Stanford: CSLI Publications.

Bjerre, T. 2006. Object Positions in a Topological Sentence Model for Danish - a Linearization-Based HPSG Approach. Presentation at Ph.D.-course at Sandbjerg, Denmark.

Borsley, R. D. 1989a. An HPSG Approach to Welsh. J. of Linguistics 25, 333354. 
Borsley, R. D. 1989b. Phrase-Structure Grammar and the Barriers Conception of Clause Structure. Linguistics 27, 843-863.

Engdahl, E., Andréasson, M. and Börjars, K. 2004. Word Order in the Swedish Midfield - an OT Approach. In F. Karlsson (ed.), Proceedings of the 20th Scandinavian Conference of Linguistics, Helsinki, January 7-9, 2004, Helsinki: University of Helsinki, Department of General Linguistics.

Engels, E. and Vikner, S. 2012. Scandinavian Object Shift and Optimality Theory. Ms, University of Aarhus.

Erteschik-Shir, N. 2005. Sound Patterns of Syntax: Object Shift. Theoretical Linguistics 31(1-2), 47-93.

Fox, D. and Pesetzky, D. 2005. Cyclic Linearization of Syntactic Structure. Theoretical Linguistics 31(1-2), 1-45.

Grover, C. 1995. Rethinking Some Empty Categories: Missing Objects and Parasitic Gaps in HPSG. Ph. D.thesis, University of Essex.

Hahn, M. 2012. Arabic Relativization Patterns: A Unified HPSG Analysis. In S. Müller (ed.), Proceedings of the 19th International Conference on HeadDriven Phrase Structure Grammar, Chungnam National University Daejeon, pp 144-164, Stanford: CSLI Publications.

Hellan, L. 1994. On Pronominal Clitics in Norwegian. In A. Holmberg and C. Hedlund (eds.), Proceedings of the XIVth Scandinavian Conference of Linguistics, pp 1-14, University of Gothenberg.

Holmberg, A. 1999. Remarks on Holmberg's Generalization. Studia Linguistica $53(1), 1-39$.

Kathol, A. and Pollard, C. J. 1995. Extraposition via Complex Domain Formation. In Proceedings of the 33rd Annual Meeting of the ACL, Boston.

Kiss, T. 1992. Variable Subkategorisierung. Linguistische Berichte 140, 256-293.

Kiss, T. 1995. Infinite Komplementation. Neue Studien zum deutschen Verbum infinitum. Tübingen: Niemeyer.

Kiss, T. and Wesche, B. 1991. Verb Order and Head Movement. In O. Herzog and C.-R. Rollinger (eds.), Text Understanding in LILOG, pp 216-242, Berlin: Springer Verlag.

Meurers, D. 2000. Lexical Generalizations in the Syntax of German Non-Finite Constructions. Arbeitspapiere des SFB 340 No. 145, Universität Tübingen.

Meurers, W. D. 1998. Raising Spirits and Assigning Them Case, vortrag auf dem Workshop Current Topics in Constraint-Based Theories of Germanic Syntax.

Meurers, W. D., Penn, G. and Richter, F. 2002. A Web-Based Instructional Platform for Constraint-Based Grammar Formalisms and Parsing. In D. Radev and C. Brew (eds.), Effective Tools and Methodologies for Teaching NLP and $C L$, pp $18-25$.

Mikkelsen, L. 2011. On Prosody and Focus in Object Shift. Syntax 14(3), 230264.

Müller, S. 1996. Yet another Paper about Partial Verb Phrase Fronting in German. In Proceedings of Coling-96, pp 800-805, Copenhagen, Denmark: ACL.

Müller, S. 1999. Deutsche Syntax deklarativ. Head-Driven Phrase Structure Grammar für das Deutsche. Tübingen: Niemeyer. 
Müller, S. 2002. Complex Predicates: Verbal Complexes, Resultative Constructions, and Particle Verbs in German. Stanford: CSLI Publications.

Müller, S. 2004. Continuous or Discontinuous Constituents? A Comparison between Syntactic Analyses for Constituent Order and Their Processing Systems. Research on Language and Computation 2(2), 209-257.

Müller, S. 2005. Zur Analyse der scheinbar mehrfachen Vorfeldbesetzung. Linguistische Berichte 203, 297-330.

Müller, S. 2007a. The Grammix CD Rom. A Software Collection for Developing Typed Feature Structure Grammars. In T. H. King and E. M. Bender (eds.), Grammar Engineering across Frameworks 2007, Stanford: CSLI Publications.

Müller, S. 2007b. Head-Driven Phrase Structure Grammar: Eine Einführung. Tübingen: Stauffenburg Verlag, first edition.

Müller, S. 2008. Depictive Secondary Predicates in German and English. In C. S. et al. (ed.), Secondary Predicates in Eastern European Languages and Beyond, pp 255-273, Oldenburg: BIS-Verlag.

Müller, S. 2009. On Predication. In S. Müller (ed.), Proceedings of the 16th International Conference on Head-Driven Phrase Structure Grammar, pp 213-233, Stanford: CSLI Publications.

Müller, S. 2013. The CoreGram Project: Theoretical Linguistics, Theory Development and Verification. Ms. Freie Universität Berlin.

Müller, S. To appear. HPSG - A Synopsis. In A. Alexiadou and T. Kiss (eds.), Syntax - Ein internationales Handbuch zeitgenössischer Forschung, Berlin: Walter de Gruyter Verlag, second edition.

Müller, S. and Ørsnes, B. In Preparation. Danish in Head-Driven Phrase Structure Grammar. Berlin: Language Science Press.

Penn, G. 2004. Balancing Clarity and Efficiency in Typed Feature Logic Through Delaying. In D. Scott (ed.), Proceedings of the 42nd Meeting of the Association for Computational Linguistics, pp 239-246, Barcelona, Spain.

Pollard, C. J. 1996. On Head Non-Movement. In H. Bunt and A. van Horck (eds.), Discontinuous Constituency, pp 279-305, Berlin, New York: Mouton de Gruyter, published version of a Ms. dated January 1990.

Pollard, C. J. and Sag, I. A. 1992. Anaphors in English and the Scope of Binding Theory. Linguistic Inquiry 23(2), 261-303.

Pollard, C. J. and Sag, I. A. 1994. Head-Driven Phrase Structure Grammar. Chicago, IL and London: University of Chicago Press.

Przepiórkowski, A. 1999. On Case Assignment and "Adjuncts as Complements". In G. Webelhuth, J.-P. Koenig and A. Kathol (eds.), Lexical and Constructional Aspects of Linguistic Explanation, pp 231-245, Stanford: CSLI.

Reape, M. 1994. Domain Union and Word Order Variation in German. In J. Nerbonne, K. Netter and C. J. Pollard (eds.), German in Head-Driven Phrase Structure Grammar, pp 151-198, Stanford: CSLI Publications.

Uszkoreit, H. 1986. Linear Precedence in Discontinuous Constituents: Complex Fronting in German. Report No. CSLI-86-47, CSLI, Stanford.

Uszkoreit, H. 1987. Word Order and Constituent Structure in German. Stanford: CSLI Publications.

Vikner, S. 2006. Object Shift. In M. E. et al. (ed.), The Blackwell Companion to Syntax, pp 392-436, Oxford: Blackwell Publishing Ltd. 